\title{
Application of Background Information Database in Drought Monitoring of Guangxi in 2010
}

\author{
Xin Yang ${ }^{1,2, *}$, Weiping $\mathrm{Lu}^{1,2}$, Chaohui $\mathrm{Wu}^{1,2}$, Yuhong $\mathrm{Li}^{1,2}$, \\ and Shiquan Zhong ${ }^{1,2}$ \\ ${ }^{1}$ Remote Sensing Application and Test Base of National Satellite Meteorology Centre, \\ Nanning, China, 530022 \\ ${ }^{2}$ GuangXi Institute of Meteorology, Nanning, China 530022 \\ GuangXi Institute of Meteorology, Nanning, 530022, P.R. China \\ Tel.: +86-771-5875207; Fax: +86-771-5865594 \\ yangxinzhuanyong@sina.com
}

\begin{abstract}
In this paper, use Nanning city as an example to show application of Background information database in drought monitoring. A near-real time drought monitoring approach is developed using Terra-Moderate Resolution Imaging Spectoradiometer (MODIS) Normalized Difference Vegetation Index (NDVI) and Land Surface Temperature (LST) products. The approach is called Vegetation Temperature Condition Index (VTCI), which integrates land surface reflectance and thermal properties. VTCI is defined as the ratio of LST differences among pixels with a specific NDVI value in a sufficiently large study area; The ground-measured precipitation data from a study area covering Nanning in Guangxi , CHINA, are used to validate the drought monitoring approach. Taking the result of drought monitoring in background information of Nanning city ,the area of farmland drought of Mild drought Moderate droughts Severe drought were 223607.2 Ha ,310596.9 Ha and 513.2 Ha.
\end{abstract}

Keywords: Background Information Database, Drought Monitoring, MODIS, Guangxi.

\section{Introduction}

Drought is a normal, recurrent feature of climate. It occurs almost everywhere, although its features vary from region to region. Drought is one of the major environmental disasters in China, whereas in recent years it have happened in mid and southern of china seriously, so it is very important to detect and monitor drought periodically at large scale for decision making. Droughts can be assessed with many kinds of indices but it is extremely difficult to quantitatively monitor and predict. Remote sensing is able to supply us with an update on crop condition over a large geographic area using a series of coarse resolution satellites and this technology has become the important means of drought monitoring. In the past decades, many methods using remote sensing information to monitor drought, such as Normalized difference

${ }^{*}$ Corresponding author.

D. Li, Y. Liu, and Y. Chen (Eds.): CCTA 2010, Part I, IFIP AICT 344, pp. 275-281, 2011.

(C) IFIP International Federation for Information Processing 2011 
vegetation index (NDVI), Vegetation Condition Index (VCI), Temperature Condition Index (TCI) and others. These indices have been developed and successfully used for monitoring drought and have the advantage in monitoring spatial and temporal variation of drought at regional, continental, and even at global scales due to their large and frequent coverage. At present, remote sensing methods for drought monitoring are mainly classified into four categories: Vegetation Index-based, Temperaturebased, Vegetation and Temperature-based, and Cloud-based. The representative indicies include Vegetation Supply Water Index (VSWI), Temperature/Vegetation Dryness Index (TVDI); Apparent Thermal Inertia Index (ATI), and Cloud Parameters Index (CPI). MODIS data is calibrated on orbit and it uses the complicated re-correcting technology to locate when it scans. Because of high-quality and effective monitoring, MODIS has become a widely used data source in drought monitoring. In this study, the vegetation temperature condition index(VTCI)model based on NDVI-LST feature space was applied to validating a series of drought disaster which occurred in Guangxi Province during the spring in 2010, and use Nanning city as an example to show application of Background information database in drought monitoring.

\section{Materials and Methods}

\subsection{Study Area}

Nanning is the capital of Guangxi autonomous region in southern China. Nanning is located in the southern part of Guangxi Zhuang Autonomous Region, $160 \mathrm{~km}$ from the border with Vietnam. It has an area of 22,293 square kilometers. The city is located on the north bank of the Yong River, the chief southern tributary of the $\mathrm{Xi}$ River, and lies some $30 \mathrm{~km}$ below the confluence of the $\mathrm{Yu}$ and the Zuo rivers. The Yong River (which later becomes the Yu River) affords a good route to Guangzhou and is navigable by shallow-draft junks and motor launches, even though it is obstructed by rapids and sandbanks. Nanning is situated in a hilly basin with elevations between 70 and $500 \mathrm{~m}$ above sea-level. Average temperature is $21.7^{\circ} \mathrm{C}$. It is often windy or breezy and very rainy, with more than $1300 \mathrm{~mm}$ of precipitation annually. It is also frost-free for all but 3 or 4 days a year and never snows.

\subsection{Data Acquisition}

In this study, MODIS images April, 8 in 2010 were required. According to remote sensing image interpretation target mark and image spectral characteristics, found remote sensing interpretation model of the background information of forest, shrub and grass, agricultural land, surface water, towns, roads from TM and ETM data from 1988 to 2008, using supervision, unsupervised, maximum classification of natural law to retrieve background information from simple to complex interpretation of each classification. Meanwhile, using human-computer interaction to refine the results. The output shp format data Vector file of disaggregated data edited in the GIS system, and get the background information on various types of remote sensing data each time(Fig. 1), then to map the agricultural land of Nanning City(Fig.2). 


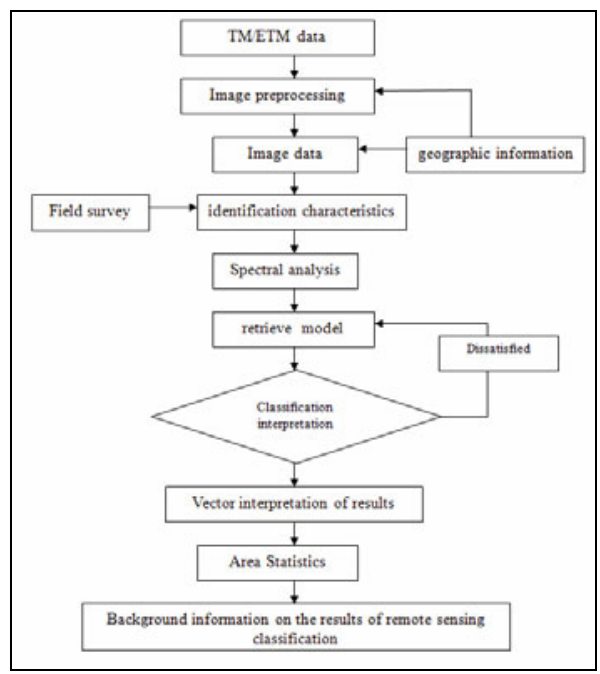

Fig. 1. The flow chart of background information of remote sensing classification

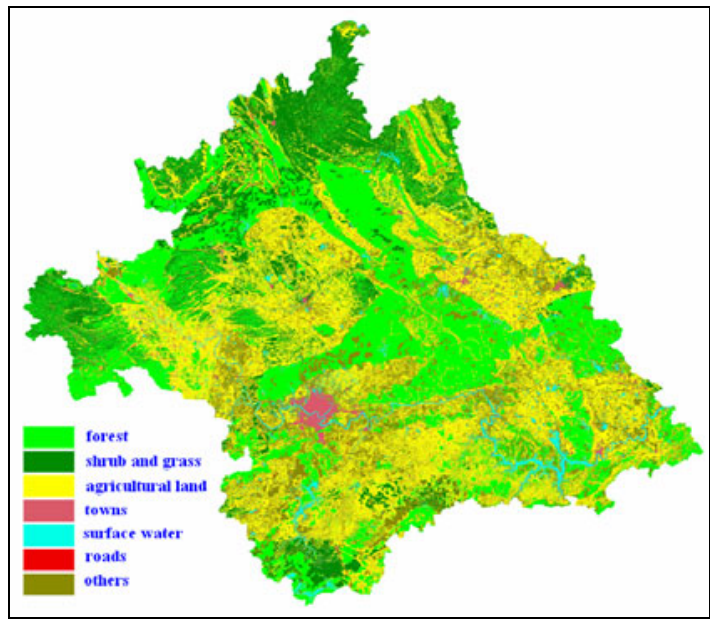

Fig. 2. Background information classes of Nanning City

\subsection{Data Processing}

Land surface temperature derived from brightness temperatures and NDVI from MODIS data are used to calculate VTCI .The temporal-spatial distribution of drought of 2010 in Nanning City in Guangxi was made by using the VTCI(Fig.3). Taking the result of drought monitoring in background information of Nanning city ,the distribution of arable land drought is made(Fig.4). 


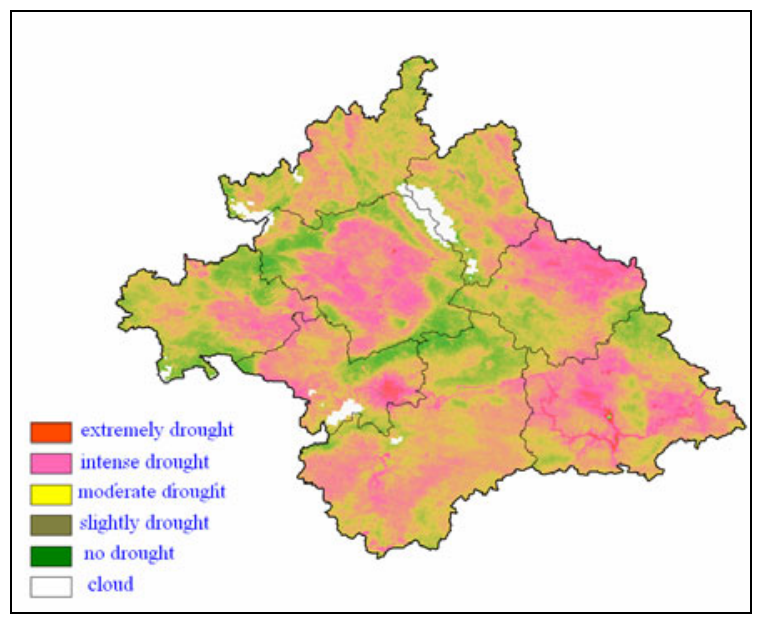

Fig. 3. Temporal-spatial distribution of drought of 2010 of Nanning City

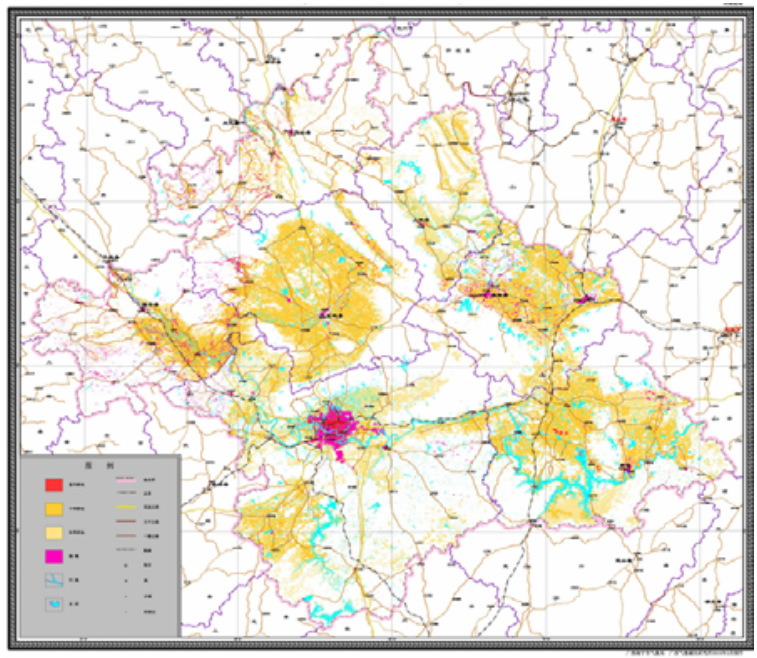

Fig. 4. Distribution of arable land drought

\section{Discussion and Conclusion}

The result of drought monitoring in background information of Nanning city shows that the area of arable land drought of Mild drought Moderate droughts Severe drought were 223607.2 Ha, 310596.9 Ha and 513.2Ha(Table 1).

The following conclusions can be reached on the basis of above analysis: Taking the result of drought monitoring in background information can provide more detailed 
Table 1. the area of arable land drought results(Ha)

\begin{tabular}{llll}
\hline & Slightly drought & Moderate drought & Intense drought \\
\hline Binyang County & 22957.2 & 52453.1 & 6.0 \\
Heng County & 34354.5 & 67289.3 & 501.4 \\
Long'an County & 17494.1 & 35137.4 & 0 \\
Mashan County & 23562.7 & 5611.5 & 0 \\
Nanning area & 66210.9 & 43871.8 & 0 \\
Shanglin & 31747.1 & 10546.8 & 0 \\
Wuming County & 27280.7 & 95687.0 & 5.8 \\
\hline
\end{tabular}

surveillance. The background information can provide services to support decisionmaking for government departments. Based on the above study and analysis, some conclusions can be drawn as follows:

1. It is an effective way to use background information in drought monitoring to provide more detailed surveillance.

2. The information of drought monitoring can support disaster assessment for government.

\section{Acknowledgments}

This research was supported by National 11th Five-Year Plan major scientific and National Key Technologies R\&D Program (2008BAD08B01) and Scientific Research and Technological Development projects of Guangxin Province (0816006-8), Sincerely thanks are also due to Guangxi Climate center and National Satellite Meteorology Center for providing the data for this study.

\section{References}

1. Wilhite, D.A., Glantz, M.H.: Understanding the drought phenomenon: the role of definitions. Water International 10(3), 111-120 (1985)

2. Nemani, R., Pierce, L., Running, S., Goward, S.: Developing satellite-derived estimates of surface moisture status. Journal of Applied Meteorology 32(3), 548-557 (1993)

3. Volcani, A., Karnieli, A., Svoray, T.: The use of remote sensing and GIS for spatiotemporal analysis of the physiological state of a semi-arid forest with respect to drought years. Forest Ecology and Management 215(1-3), 239-250 (2005)

4. Tadesse, T., Brown, J.F., Hayes, M.J.: A new approach for predicting drought-related vegetation stress: integrating satellite, climate, and biophysical data over the U.S. central plains. ISPRS Journal of Photogrammetry and Remote Sensing 59(4), 244-253 (2005)

5. Bajgiran, P.R., Darvishsefat, A.A., Khalili, A., Makhdoum, M.F.: Using AVHRR-based vegetation indices for drought monitoring in the Northwest of Iran. Journal of Arid Environments 72(6), 1086-1096 (2008)

6. Jeyaseelan, A.T., Kogan, F.N.: Evaluation of GVI based indices for drought early warning in India. In: Disaster Forewarning Diagnostic Methods and Management. Proceedings of SPIE, vol. 6412, pp. 4120-4120 (2006) 
7. Marshall, G., Zhou, X.: Drought detection in semiarid regions using remote sensing of vegetation indices and drought indices. In: Proceedings of the International Geoscience and Remote Sensing Symposium (IGARSS 2004), September 2004, vol. 3, pp. 1555-1558 (2004)

8. Liu, L., Xiang, D., Dong, X., Zhou, Z.: Improvement of the drought monitoring model based on the cloud parameters method and remote sensing data. In: Proceedings of the 1st International Workshop on Knowledge Discovery and Data Mining (WKDD 2008), pp. 293-296 (2008)

9. Mo, W., Wang, Z., Sun, H., Ma, L., He, L.: Remote Sensing Monitoring of Farmland Drought Based on Vegetation Supply Water Index. Journal of Nanjing Institute of Meteorology 29(3), 396-401 (2006)

10. Naira, C., Robert, L., Ramata, M., Marouane, T.: Surface soil moisture status over the Mackenzie River Basin using a temperature/vegetation index. In: Proceedings of the International Geoscience and Remote Sensing Symposium (IGARSS 2007), pp. 1846-1848 (2007)

11. Patel, N.R., Anapashsha, R., Kumar, S., Saha, S.K., Dadhwal, V.K.: Assessing potential of MODIS derived temperature/vegetation condition index (TVDI) to infer soil moisture status. International Journal of Remote Sensing 30(1), 23-39 (2008)

12. Li, W., Mao, S.Y., Chen, W.: A new method of cloud detection in MODIS image. In: Proceedings of the 7th International Conference on Electronic Measurement and Instruments, vol. 7, pp. 281-285 (2005)

13. Cai, G.: MODIS data based thermal inertia and land surface temperature modeling and their applications in determination of soil moisture and heat exchange, doctoral dissertation,M.S. thesis, Institute of remote sensing applications Chinese academy of sciences, Advances in Artificial Intelligence, vol. 10 (2006)

14. Liu, L., Xiang, D., Zhou, Z., Dong, X.: Analyses the modification functions of the drought monitoring model based on the cloud parameters method. In: Proceedings of the 1st International Congress on Image and Signal Processing (CISP 2008), vol. 4, pp. 687-691 (2008)

15. Reed, B.C., Brown, J.F., VanderZee, D., Loveland, T.R., Merchant, J.W., Ohlen, D.O.: Measuring phenological variability from satellite imagery. Journal of Vegetation Science 5(5), 703-714 (1994)

16. Hamel, S., Garel, M., Festa-Bianchet, M., Gaillard, J.-M., Côté, S.D.: Spring Normalized Difference Vegetation Index (NDVI) predicts annual variation in timing of peak faecal crude protein in mountain ungulates. Journal of Applied Ecology 46(3), 582-589 (2009)

17. Kerr, J.T., Ostrovsky, M.: Fromspace to species: ecological applications for remote sensing. Trends in Ecology \& Evolution 18(6), 299-305 (2003)

18. Julien, Y., Sobrino, J.A.: The Yearly Land Cover Dynamics (YLCD) method: an analysis of global vegetation from NDVI and LST parameters. Remote Sensing of Environment 113(2), 329-334 (2009)

19. Sandholt, I., Rasmussen, K., Andersen, J.: A simple interpretation of the surface temperature/vegetation index space for assessment of surface moisture status. Remote Sensing of Environment 79(2-3), 213-224 (2002)

20. Qi, S., Wang, C., Niu, Z.: Evaluating soil moisture states in China using the temperature/vegetation dryness index (TVDI). Joutnal of Remote Sensing 15, 420-427 (2003)

21. Li, W., Li, D.: The universal cloud detection algorithm of MODIS data. In: Geoinformatics 2006: Remotely Sensed Data and Information. Proceedings of SPIE, vol. 6419, p. 4190 (October 2006) 
22. Li, C., Li, H.: Study on winter wheat drought monitoring by TVDI in Hebei Province. In: Remote Sensing and Modeling of Ecosystems for Sustainability III, San Diego, Calif., USA, August 2006. Proceedings of SPIE, vol. 6298, pp. 2981-2981 (2006)

23. Jin, C., Qin, Q.M., Zhu, L., Nan, P., Ghulam, A.: TVDI based crop yield prediction model for stressed surfaces-a case study on Ningxia Huizu autonomous region of China. In: Proceedings of the International Geoscience and Remote Sensing Symposium (IGARSS 2008), pp. 4656-4658 (2008) 